\section{"Tú, como eres negra, harás de lobo". El debate pendiente sobre la cuestión de la raza en España.}

\author{
DAN RODRÍGUEZ-GARCÍA ${ }^{1}$
}

0000-0002-1117-292X

Universitat Autònoma de Barcelona, España

TERESA HABIMANA-JORDANA²

0000-0002-5300-609X

Universitat Autònoma de Barcelona, España

\section{CRISTINA RODRÍGUEZ-RECHE ${ }^{3}$}

0000-0001-6646-7605

Universitat Autònoma de Barcelona, España

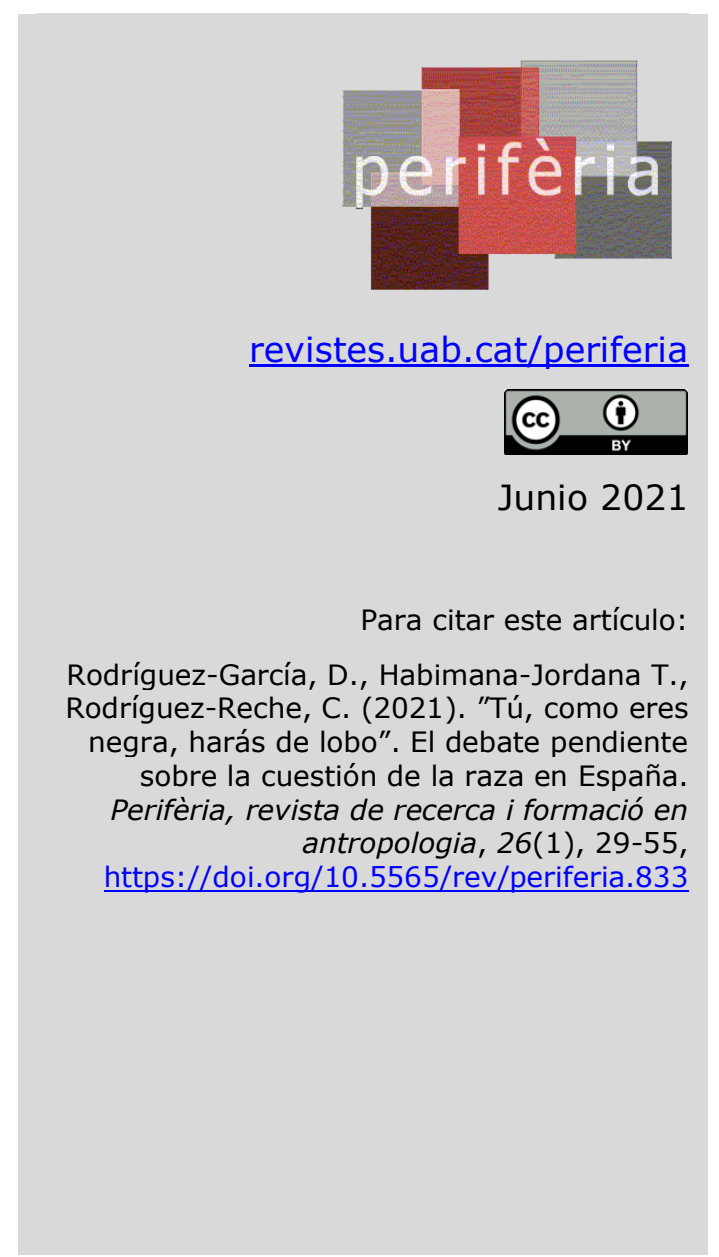

\title{
Resumen
}

En este artículo argumentamos que la idea de "raza" constituye un factor fundamental para la atribución de la pertenencia y el tratamiento social diferencial en España. Tras operacionalizar algunos conceptos clave (raza, racismo y racialización), ofrecemos una contextualización histórica y social sobre la construcción de la idea de raza en España, y aportamos datos sociodemográficos sobre la prevalencia del racismo en la sociedad española. En segundo lugar, aportamos información de tipo etnográfico. A través del análisis de narrativas de descendientes de uniones mixtas residentes en España, ejemplificamos hasta qué punto la idea de raza juega un papel central en las experiencias de estigmatización y discriminación de una parte cada vez más importante de la población española.

Palabras clave: Raza; Racismo; Racialización; Colonialismo; Inmigración; Mixticidad; Pertenencia; Exclusión social.

\footnotetext{
${ }^{1}$ Contacto: Dan Rodríguez-García - dan.rodriguez@uab.cat

2 Contacto: Teresa Habimana-Jordana - nyiraberateresa.habimana@uab.cat

${ }^{3}$ Contacto: Cristina Rodríguez-Reche - cristina.rodriguez.reche@uab.cat
} 
Abstract: "Since you are Black, you'll play The Wolf". The pending debate on the issue of "race" in Spain.

In this article we argue that the idea of 'race' constitutes a fundamental factor for the attribution of membership and differential social treatment in Spain. After operationalizing some key concepts (race, racism and racialization), we offer a historical and social contextualization on the construction of the idea of race in Spain, and we provide sociodemographic data on the prevalence of racism in Spanish society. Second, we provide ethnographic information. Through the analysis of narratives of descendants of mixed unions residing in Spain, we exemplify the extent to which the idea of race plays a central role in the experiences of stigmatization and discrimination of an increasingly important part of the Spanish population.

Keywords: Race; Racism; Racialization; Colonialism; Immigration; Mixedness; Belonging; Social exclusion.

\section{Sobre la definición de raza, racismo y racialización}

Cabe empezar señalando que el concepto científico de "raza", fabricado en el siglo XVIII, y según el cual los humanos se dividen biológicamente en diferentes taxonomías o en tipos esenciales de individuos en función de los rasgos percibidos, no tiene base científica (Lewontin et al., 1985). La humanidad pertenece a una sola especie (Homo Sapien Sapiens), y la creencia de que existen diferentes capacidades para producir cultura basadas en diferencias genotípicas y fenotípicas, como propuso el Darwinismo Social, es una falacia. El racismo ${ }^{4}$ se basa justamente en esta creencia de clasificación y jerarquización de los seres humanos en función de criterios biológicos y de herencia, para justificar desigualdades sociales en base a la interpretación de esas diferencias.

\footnotetext{
4 Todorov (1989) distingue entre 'racismo', como comportamiento transcultural, y 'racialismo', que sería la doctrina o movimiento teórico-científico de elaboración de la idea de raza, nacido en Europa occidental a mitades del siglo XVIII, hasta mitades del siglo XX, y que deriva de los trabajos de Linneo (System of Nature, 1735), Buffon (Histoire naturelle, 1749-1789), y el Conde de Gobineau (Essai sur l'inégalité des races humaines, 1853), culminados por Darwin en Origin of Species (1859). El racismo biológico puede también mutar en un "nuevo racismo" (Barker, 1981) o "neo-racismo diferencialista" (Taguieff, 1987), donde la cultura reemplaza la idea de la raza biológica como base para la jerarquización y discriminación. Sobre la relación entre raza y cultura o etnicidad, véase Molina y Rodríguez-García (2018).
} 
Sin embargo, aunque las razas no existan biológicamente, las consecuencias de ese constructo-el racismo y la racialización-sí son muy reales. Como señala BonillaSilva (1999), la raza es un hecho social que tiene efectos reales en la vida de las personas. Y esto se debe a que la idea de raza está incrustada estructuralmente en las instituciones sociales, políticas, económicas y culturales (véase también Chun y Lo, 2015; Hall, 1980; Goldberg, 2002; Grosfoguel, 2004; Song, 2018). La idea de raza es, pues, "una ficción biológica con una función social" (Hughey, 2017, p.27).

Como corolario de la idea de raza, la racialización es el trato diferencial de un individuo o grupo basado en una categoría racial atribuida socialmente, basada en características visibles percibidas (como el color de piel, la vestimenta u otros aspectos de la apariencia), o en distinciones culturales (como el idioma o la religión), y las suposiciones que se hacen en torno a estas diferencias (Barot y Bird, 2001; Gans, 2017; Murji y Solomos, 2005; Hochman, 2019; Chun y Lo, 2015). La racialización también se refiere a la legitimación, racionalización y justificación del racismo o la distribución sistemática, jerárquica y desigual de los recursos y el trato desigual de las personas una vez racializadas (Campos, 2012; Gross y Hughey, 2017). En esta esencialización de las características individuales o grupales en términos raciales, juega un papel fundamental el fenotipo; esto es, los "aspectos de la apariencia física, ya sean 'reales' o imaginarios y típicamente cristalizados en estereotipos étnicos" (Jenkins, 1997, p. 65). Así, por ejemplo, Grosfoguel (2004) explica cómo la racialización de los puertorriqueños en Nueva York se basa en gran medida en características visibles como la negritud. Si bien el concepto de racialización se asocia principalmente con el contexto post-colonial (Balibar y Wallerstein, 1991), donde las clases dominantes asignan un estatus inferior al color de piel más oscuro, las poblaciones que no estaban sujetas a la historia colonial o que no eran consideradas "personas de color" también han sido racializadas, como los irlandeses en los Estados Unidos o los musulmanes y judíos (Goldberg, 2002; 2006).

Un ejemplo que muestra a la vez la importancia del fenotipo-en particular del color de la piel (Hunter, 2007; Martin et al., 2017; Price 2012)-y de la arbitrariedad de la idea de raza, es el reportaje del magazine National Geographic de abril de 2018, titulado "Blanco y negro", y que presentaba en su portada a dos hijas gemelas de una pareja mixta anglo-jamaicana, siendo una de las gemelas fenotípicamente negra, 
mientras que la otra es aparentemente blanca debido a su color de piel claro y cabello rubio $^{5}$. Este caso es revelador de cómo la negritud es una categoría racial que se construye en relación con otra que es la blanquitud, según Lentin (2020) la "categoría racial primordial" (véase también Beaman, 2019; Lewis, 2004). Es importante aquí diferenciar entre racismo (un sistema histórico y estructurado de dominación) de la noción más amplia de racialización, que de hecho ha sido útil para la comprensión de los incidentes raciales en toda su complejidad (Song 2014b). Es decir, las personas blancas pueden de hecho ser racializadas, siendo objeto de prejuicios y estereotipos basados en el color de su piel. Sin embargo, este tipo de racialización no equivale a racismo, debido al desequilibrio sistémico inherente de poder entre las personas de color de piel más claro y las personas de color. El racismo existe solo cuando hay una estructura de poder ponderada a favor de una 'raza' en particular. Históricamente, la mayoría blanca ha tenido el poder cuando se trata de divisiones raciales, mientras que las personas de color han sido las que se han enfrentado al racismo y la opresión sistémicos y estructurales.

\section{¿Hablar de "raza" en España? Contexto histórico y social}

¿Tiene sentido hablar de "raza" 6 en la sociedad española actual? Esta es la pregunta que guía este trabajo.

En países como los Estados Unidos, donde predomina la división entre blancos y negros, debido al legado de la esclavitud, y en países de la Commonwealth (que comparten lazos históricos con el Reino Unido), el término raza se sigue utilizando como concepto analítico y categoría folk de activismo social, para resaltar la importancia del color de piel en las dinámicas de inclusión y exclusión social. El etiquetado racial en países como Estados Unidos está incrustado en la cultura, originalmente como una herramienta de opresión, y luego como un intento de ciertos grupos de reapropiarse de términos raciales por razones de empoderamiento $y$ antidiscriminación. La población negra de Estados Unidos ha sido también

5 Véase: https://www.nationalgeographic.com/magazine/2018/04/race-twins-black-white-biggs/ ; http://www. mixedracestudies.org/?p=55862

\footnotetext{
${ }^{6}$ Nos referimos siempre a la idea o la construcción sobre la 'raza', de ahí que, aunque no se haga en todas las ocasiones para facilitar la lectura, el término debe entenderse siempre en un sentido figurado.
} 
denominada "de color" (colored), "negros" (Black, Negroes), o "Afroamericanos" (African Americans) dependiendo del momento histórico, y actualmente algunos grupos no blancos usan el término BIPOC (Black, Indigenous and People of Color) para resaltar la relación única que tienen los negros, los indígenas (pobladores originarios) y las personas de color con la blanquitud de los descendientes de anglosajones.

En España, como en el resto de Europa, en cambio, el término raza, ha sido un concepto tabú desde el final de la Segunda Guerra Mundial, tanto en el discurso académico como en el político, y se ha tendido a substituirlo por el de "etnia" o, aún más eufemísticamente, "origen". La mayoría de los países de Europa adoptan un enfoque antirracista clásico, según el cual se considera que hacer distinciones étnicas o raciales es la raíz del racismo y que, por tanto, la igualdad se logra mediante la invisibilización de las diferencias.

Sin embargo, el tema de la raza no está ausente ni en España ni en el resto de Europa. A pesar de que ambas se piensen a sí mismas como sociedades post-raciales, las políticas y los discursos nacionales sobre razas y relaciones raciales de tiempos pasados (coloniales) todavía tienen un impacto importante en las sociedades europeas contemporáneas, donde el racismo y la racialización siguen estando muy presentes. Aunque España no sea una sociedad estrictamente pigmentocrática como Ios Estados Unidos o Brasil (Telles, 2014; Telles y Paschel, 2014), y al igual que ocurre en otros países de Europa (para el caso de Francia, véase Simon, 2019; Brinbaum et al., 2018 y Beaman, 2019; 2020; para el caso del Reino Unido, véase Song, 2018; y para Europa en general véase European Union Agency for Fundamental Rights, 2018) o del otro lado del Atlántico (Alba y Foner, 2015; Hunter, 2007; Martin et al., 2017; Price, 2012), numerosos estudios muestran que el color de la piel y otros rasgos físicos interpretados como atributos de raza, son, no obstante, marcadores cruciales para la interacción social, la inclusión/exclusión social y el trato diferencial en España (Cornejo, 2007; Flores, 2015; Giliberti, 2013).

Varios estudios recientes realizados por la Federación de Asociaciones SOS Racismo (2015, 2019) concluyen que la discriminación en España por el color de la piel es abrumadora. El primer estudio (2015) reporta prácticas discriminatorias en el acceso a la vivienda, señalando una diferencia considerable en la negativa a alquilar pisos a la población nacida en el extranjero "distinguible" en comparación con la población 
nativa de origen español (70\% versus 30\%, respectivamente). El segundo estudio (2019) advierte sobre la discriminación basada en las paradas policiales según el perfil étnico: en 2017, en Cataluña, el 54,1\% del total de las detenciones policiales de los Mossos d'Esquadra (policía autónoma de Cataluña) involucraron a personas nacidas en el extranjero, un grupo que supone solo el 13,7\% del total de la población catalana. Otro estudio reciente centrado en el municipio de Barcelona (Ajuntament de Barcelona, 2020), también señala que, con el con el 33\% de los casos reportados, la principal causa de discriminación en Barcelona se debe al racismo y la racialización, mayormente hacia personas magrebíes y negro-africanas, algo que ocurre también en países como Francia, donde la discriminación en base al color de piel es la forma más común de discriminación, afectando particularmente a la población afrodescendiente (también magrebí), a pesar de ser población nacida y socializada en Francia (Brinbaum, Safi y Simon, 2018). Finalmente, según el informe del Gobierno español sobre Percepción de la discriminación por origen racial o étnico por parte de sus potenciales víctimas en 2020 CEDRE (2020), que recoge datos de una encuesta a 1.600 personas de ocho grupos étnico-raciales diferentes (Roma, Magreb, Indo- Paquistaníes, asiáticos del este, andinos, europeos del este, africanos no mediterráneos y afrodescendientes) sobre la percepción de discriminación en diferentes ámbitos (educación pública, sistema de salud, administración pública, acceso a la vivienda, tratamiento policial, etc.), más de la mitad de la población racializada de España $(51,8 \%)$ ha manifestado que se ha sentido discriminada en el último año. Desde el informe anterior de 2013, la percepción de discriminación ha aumentado en casi todos los ámbitos.

En España, esta realidad sólo puede explicarse por el hecho de que se trata de una sociedad impregnada-a todos los niveles de la estructura social-de la idea de raza vinculada a la historia colonial del país. La construcción de la raza y de la "blanquitud"7 en España se remonta al menos al siglo XIII, con la noción de "pureza de sangre", una doctrina católica de distinción esencial-moral entre cristianos y no cristianos (musulmanes y judíos). Así pues, antes de ser vista como una categoría científica en el siglo XVIII, la idea de raza se formuló como una categoría de estatus

\footnotetext{
7 Según Lentin (2020) la categoría "blanco" es la categoría racial primordial en relación a la cual se construye la la categoría de "negro" y de "negritud". Véase también Beaman (2019), Lewis (2004).
} 
moral y social, para proteger los privilegios de clase. Ya en el siglo XV, con la implementación de los Estatutos de limpieza de sangre, se buscará más claramente asegurar que solo las personas de ascendencia cristiana (los llamados "cristianos viejos", interpretados como "blancos puros") pudieran avanzar socialmente y mantener posiciones de poder sobre las denominadas "malas razas", es decir, los judíos, "moros" y conversos en la España peninsular, y los negros, nativos americanos y mestizos en las colonias españolas (Méchoulan, 1981). Así, en la América colonial del siglo XVI, se creó un sistema de castas que emparejaba el color de la piel y la raza asignada con el grado de derechos y participación social que tendría el individuo, un sistema que regiría toda la organización social y económica de las colonias. La posición social de la familia (su honor) se basaba en mantener la integridad de la pureza de sangre en su linaje. En este contexto, la mezcla de castas a través del matrimonio fue considerada sinónimo de degradación moral y social (Rodríguez-García, 2021), y supuso un problema para el mantenimiento del orden social.

Los estándares de pureza racial solo fueron abolidos por completo en 1870. Más tarde, durante la dictadura de Franco (1939-1975), la preocupación del régimen gobernante fue regenerar moralmente lo que se denominó "la raza española" a través de un proyecto de catolicismo nacional y un renacimiento de tradición española "auténtica". La noción de "hispanidad" promulgada no estaba definida por categorías raciales per se, pero era altamente insular, definida por el catolicismo y profundamente antagónica a los elementos "extranjeros" (Campos, 2016). Y desde la década de 1980, en los esfuerzos posteriores al franquismo de España para afirmarse como una nación europea moderna y civilizada que pertenecía a la Unión Europea, se reanudó la imaginación y la definición de la sociedad y la identidad españolas como fundamentalmente "blancas".

Es importante señalar aquí el papel que tuvo el catolicismo español en la construcción de la idea de raza, pues bajo la apariencia de inclusión y ambición apostólica universalista, hubo una doble lógica de exclusión basada en la extranjerización de las otras confesiones (judaísmo e islam), enemigas absolutas sobre las que recaían todos los estereotipos, incluso una vez convertidos como "cristianos nuevos", es decir, ciudadanos de segunda categoría. La combinación de estas dos dinámicas (de inclusión y discriminación) es característica del racismo español de base católica. 
Esta historia de la relación de España con la idea de raza está muy poco visibilizada. Se obvia el hecho de que España colonizó no solo las Américas, sino también partes de Asia y África, en este último caso donde tuvo colonias en Marruecos y Guinea Ecuatorial hasta finales de la década de 1960. Por no mencionar la histórica limpieza étnico-religiosa que tuvo lugar con los judíos, musulmanes y gitanos. La impactante realidad es que en España y en sus colonias se vendieron esclavos negros hasta fecha tan tardía como 1846, ventas que se anunciaban en los periódicos en la sección "Venta de animales"8. Las guerras simbólicas entre "moros y cristianos" todavía se representan hoy en las escuelas y fiestas populares de toda España para conmemorar la Reconquista de España por los cristianos. Y existen, todavía hoy, productos de consumo popular que dan cuenta de la profunda internalización y normalización del imaginario racial colonial en España. Un ejemplo en el ámbito de la alimentación es el Cola Cao, la bebida de chocolate por excelencia en España, cuya publicidad, recordada con nostalgia por muchos españoles, solía utilizar una canción que retrataba a los esclavos felices trabajando en las plantaciones de cacao ${ }^{9}$.

Otro ejemplo son los Conguitos (que se traduciría por "pequeña gente del Congo"), una marca española muy popular de dulces que consiste en cacahuetes cubiertos de chocolate $^{10}$. El caso de Conguitos en particular es muy revelador de hasta qué punto los estereotipos y prejuicios racistas sobre la población negro-africana en iconografía de los envases y anuncios publicitarios han perdurado a lo largo de las décadas ${ }^{11}$ : inicialmente, en la década de los 1960s, los envoltorios y anuncios presentaban imágenes colonialistas de salvajes africanos en sus chozas (siempre con rasgos caricaturizados, especialmente labios de gran tamaño); en décadas más recientes, se han incorporado las referencias a la cultura hip-hop y a los deportes como el baloncesto, manteniendo siempre un fuerte estereotipo que inferioriza a la población negra. El hecho de que todos los rostros y personajes que aparecen en la publicidad

\footnotetext{
${ }^{8}$ Véase https://www.bbc.com/mundo/noticias-46870271

9 Véase anuncio promocional de Cola-Cao de principios de los años 1960s disponible en: https://www.youtube.com/watch?v=pce-KGGUYaM

10 Véase anuncio promocional de Conguitos de principios de los años 1990s disponible en: https://www.youtube.com/watch?v=baRogIEg930

11 Para una evolución de los anuncios publicitarios sobre este producto, véase https://www. youtube.com/watch? $v=C 7 \times x 011 \mathrm{coJk}$
} 
de los Conguitos sean siempre negros y que se los ofrezca para ser comidos o consumidos por una mayoría blanca, envía un mensaje doblemente perturbador sobre las relaciones de poder en la sociedad española. La mayoría de los españoles, jóvenes y mayores, pasan por alto esta forma normalizada de lo que se ha denominado "racismo cotidiano" (Essed, 1991), "racismo sutil", o "micro agresiones" (Sue, 2010); pero racismo, al fin y al cabo.

Teniendo todo esto en cuenta, no es sorprendente que todavía sea un insulto común que los niños en la escuela llamen a sus compañeros negros "Cola Cao" o "Conguitos" y a sus compañeros musulmanes "moros" (véase Ballestín González 2011, 2012; Rodríguez-García y Miguel Luken 2015; Rodríguez García et al. 2018, 2021b). Y estos ejemplos son solo algunos de los muchos indicios que podríamos encontrar sobre los constructos raciales y el racismo presentes en la cultura popular española.

En suma, a pesar de la clara persistencia de la idea de raza, la racialización y el racismo en la sociedad española, existe una falta total de conciencia y compromiso en torno a este debate, como si el problema simplemente desapareciera al no hablar de ello (Lentin, 2008; 2020).

\section{La mixticidad como prueba crucial de la persistencia de la idea de raza en España}

Sí hay un ámbito de estudio decisivo donde poder rastrear los constructos en torno a la raza, este es el de la mixticidad ${ }^{12}$. Las uniones entre personas del mismo grupo, ya sea en términos de raza, etnia, nacionalidad, religión o clase social, han sido históricamente promovidas social e institucionalmente, mientras que las uniones mixtas que cruzan esas fronteras han sido problematizadas e incluso prohibidas, y sus descendientes estigmatizados. Por esta razón el estudio de la mixticidad es

\footnotetext{
12 Utilizamos aquí el término 'mixticidad' (derivado del francés 'mixité' y del inglés 'mixedness' y 'mixity') como un concepto abarcador que se refiere a las uniones y familias mixtas a través del cruce de categorías etnoculturales, raciales, religiosas o de clase, así como a los procesos socioculturales implicados (construcciones políticas, actitudes sociales y procesos cotidianos de hibridismo sociocultural -García Canclini, 1995-), entendiendo estos procesos como un "tercer espacio" de negociación que perturba y cuestiona las normas y categorías sociales (Rodríguez-García 2015, p.11). Obviamente, la noción de 'mixto', como la de 'raza', es una noción contestada y dependiente del contexto en el espacio y el tiempo; es decir, producto de contextos históricos, sociales y políticos determinados (Ibid.).
} 
altamente relevante para exponer las fronteras entre grupos sociales y determinar la estructura de una sociedad (Rodríguez-García, 2015; 2021). La idea de "mezcla" expone la construcción de las categorías de diferenciación social, pues es en los límites, en la frontera, y en el cruce de categorías y espacios intermedios, donde se pueden identificar y analizar mejor las categorías de diferenciación entre personas y grupos.

El caso de España es particularmente relevante para este tipo de estudios, pues, además de contar con una importante historia colonial, en las últimas décadas, y en paralelo un período de inmigración sin precedentes (Arango, 2013), ha experimentado un incremento $y / 0$ diversificación de las uniones mixtas 0 binacionales, así como el número de descendientes de esas uniones, especialmente en Cataluña, una de las regiones con mayor índice de inmigración de España (Rodríguez-García et al. 2021a).

\section{Apuntes metodológicos}

La información etnográfica que presentamos a continuación procede de una investigación con varios proyectos concatenados realizados entre 2014 y 2020, donde se ha aplicado una metodología fundamentalmente cualitativa consistente en trabajo de campo etnográfico, entrevistas en profundidad y grupos focales ${ }^{13}$.

La muestra, obtenida con un muestreo por cuotas y el método de bola de nieve, está

\footnotetext{
${ }^{13}$ Sociabilidad y procesos identitarios de hijos/as de uniones mixtas: la mixticidad, entre la inclusión y la constricción social", financiado por el Ministerio de Economía y Competitividad, Programa Retos de la Sociedad (CSO2015-63962-R, 2016-20); "Jóvenes en familias mixtas y religión: dinámicas de identidad y mixticidad religiosa en Cataluña", financiado por la Agencia de Gestión de Ayudas Universitarias e Investigación de la Generalitat de Catalunya (2015RELIG00025, 2016-17); "Inmigración y Uniones Mixtas: Etnicidad e Integración Social", financiado por el Ministerio de Ciencia e Innovación Programa Excelencia (CSO2011-23242, 2012-15); e "Identidad y dinámicas de interculturalidad de jóvenes en familias binacionales en Cataluña: un aspecto clave para la cohesión social" (2014) y "Niños y jóvenes de parejas bi-nacionales en Cataluña: entre la elección y la constricción identitaria" (2015), ambos financiados por el Institut d'Estudis Catalans (IEC). Agradecemos aquí todas las ayudas recibidas. La información etnográfica sobre asociacionismo africano y religión también se nutre de dos tesis doctorales en curso, llevadas a cabo por las co-autoras de este artículo "Trayectorias de vida y espacios cotidianos de mujeres afrodescendientes en Cataluña: Un estudio interseccional sobre la mixicidad y los procesos de identidad", de Teresa Habimana Jordana, e "Hijas de uniones mixtas con un padre/madre inmigrante de origen magrebí en Barcelona y Granada: identidad, mixticidad, género y alcance del estigma de la musulmaneidad", de Cristina Rodríguez Reche, ambas co-dirigidas por Dan Rodríguez-García y realizadas dentro del proyecto "Sociabilidad y procesos identitarios de hijos/as de uniones mixtas" (CSO2015-63962R).
} 
formada por 152 personas ${ }^{14}$ residentes y mayoritariamente nacidos y/o criados en Cataluña. De estos 59 son hombres y 93 mujeres, de entre 14 y 29 años, y con orígenes familiares muy diversos (hay 51 países representados). Esto incluye a 97 hijos con un padre nacido en España y el otro en un país extranjero, a 22 hijos con padres nacidos en dos países extranjeros distintos, a 28 hijos con ambos padres nacidos en el mismo país extranjero, y a 5 con ambos progenitores y abuelos nacidos en España (estos dos últimos grupos se utilizaron como grupos de control). De esta forma, nuestra muestra va más allá de la dicotomía mayoría/minoría o nativo/inmigrante, lo cual permite un análisis más complejo y profundo.

El guion de la entrevista incluyó un exhaustivo cuestionario sociodemográfico, seguido de preguntas abiertas relacionadas con una gran variedad de temas, entre ellos: trayectoria migratoria de los padres inmigrantes, vida familiar, costumbres, creencias y prácticas religiosas, escuela, inserción laboral, participación política, ocio, amistades, capital lingüístico, relaciones familiares transnacionales, identidad y sentido de pertenencia, experiencias de discriminación, y planes de futuro. Todas las se grabaron digitalmente, y posteriormente se transcribieron y analizaron con el software ATLAS.ti ${ }^{15}$.

Por razones de espacio, ofrecemos aquí solo un análisis descriptivo y parcial, centrado en la cuestión de la visibilidad en relación con la construcción de la idea de raza, que creemos que complementa y ejemplifica bien la información ofrecida en los apartados anteriores. ${ }^{16}$

\footnotetext{
14 Hasta donde conocemos, esta es la mayor muestra cualitativa de esta naturaleza en el mundo.

15 ATLAS.ti es un software utilizado sobretodo, pero no exclusivamente, en el análisis de datos cualitativos de alto volumen. El programa proporciona herramientas para que los investigadores creen códigos para temas, busquen correlaciones entre ellos, y evalúen su relevancia.

16 Para análisis más pormenorizados, con explotación cuantitativa de los datos y triangulación, véase Rodríguez-García et al. 2018, 2021b.
} 


\section{La pervivencia de la idea de raza en los procesos de mixticidad: visibilidad y discriminación.}

El principal hallazgo que queremos presentar aquí es que los procesos de racialización y las experiencias de discriminación se relacionan en gran medida con el origen y la visibilidad social de la condición de inmigrante. Por un lado, encontramos individuos que, independientemente de si son mixtos o no, podrían "pasar por autóctonos" (españoles nativos) porque compartían ciertas características externas que les asemejan a la mayoría y que son socialmente prestigiosas (e.g., el tono de piel blanco). Asimismo, aquellos individuos con progenitores (uno o ambos) cuyo país de origen tenía un estatus más alto en la sociedad española (predominantemente personas de países ricos de Europa occidental, América del Norte y Asia) a menudo se encontraban en una posición social de mayor prestigio y ventaja debido a sus características culturales diferenciales valorizadas, como podría ser el idioma extranjero (p.ej., inglés, francés, italiano o chino). En este grupo, la experiencia de mixticidad solía ser ventajosa, con un uso flexible y estratégico de su identidad mixta, que les permitía viajar entre países, aprovechar diversas redes personales, utilizar múltiples idiomas y disfrutar de un estatus multiétnico que era visto como "exótico" o "cosmopolita".

Por el contrario, aquellos descendientes de parejas mixtas o endógamas cuya herencia etnoracial implicaba a un grupo o cultura de bajo prestigio social, y que poseían marcadores visibles estigmatizados en base a estereotipos y prejuicios históricamente construidos sobre ese origen o grupo (e.g., un color de piel oscuro, elementos de indumentaria islámica como el hijab, o nombres, acentos o idiomas no valorados socialmente, como el árabe o el urdu), tenían una experiencia de mixticidad más limitada o negativa, donde la auto-identificación como "catalán", "español" o "mixto" no coincidía con las categorías racializadas y extranjerizadoras asignadas de "inmigrante", "negro" o "musulmán", resultando su capital sociocultural mixto más limitado o condicionado desde el exterior.

Los siguientes dos ejemplos de narrativas ejemplifican bien el racismo y la racialización que algunos de nuestros entrevistados han experimentado en función 
de su fenotipo:

"[Mis hijas] son de aquí. Han nacido y se han criado aquí, se sienten de aquí, solamente de aquí, pero las ven como extranjeras (...) También, por ejemplo, hubo una profesora de tercero que hacían la obra La Caperucita Roja, que le dijo [a mi hija de 8 años]: "Tú como eres negra, harás de lobo". Esa vez fui y me quejé a la directora". Mujer dominicana casada con un hombre español. ${ }^{17}$

"Si me tengo que definir yo diría soy un chico negro nacido en España. No me siento [español] porque no me lo han hecho sentir. Todo eso al final te va... te haces una coraza también. Aquí los catalanes o españoles no me ven catalán ni español, y yo me veo catalán y español. Recuerdo un comentario de un compañero de trabajo que me hizo ilusión en cierta manera; me dijo que era un logro que hubiera un negro trabajando en la Cruz Roja. Me hizo reflexionar, porque la situación de los negros en España es de tan poco poder que cualquier mínima conquista significa mucho (...) A mí me hubiese gustado siendo niño haber tenido un profesor negro, un médico negro, no ver solo negros en..." Hombre, 29 años, madre española y padre guineano.

El siguiente ejemplo muestra cómo, además de rasgos físicos como el color de la piel, la vestimenta no convencional, especialmente las prendas que pueden tener ciertas afiliaciones etno-religiosas, produce una reacción excluyente de la sociedad española dominante:

"Tengo dashikis [prenda de vestir colorida que cubre la mitad superior del cuerpo, ampliamente utilizada en África occidental] que me trae mi pareja (...) A veces me pongo eso, me pongo un turbante y salgo a la calle. iEntonces cambia mucho como me tratan, eh! (...) Me saludan más negros, y los blancos me esquivan la mirada" Mujer, 18 años, madre colombiana y padre brasileño.

En cuanto a la experiencia de la disonancia identitaria (la diferencia entre la identidad auto-escogida y la socialmente asignada), los siguientes extractos de

\footnotetext{
17 En todos los casos, los países de los padres son los de nacimiento, no de nacionalidad.
} 
entrevistas demuestran el papel fundamental que juega la apariencia física en este fenómeno:

"Si no hablo, me ven como una extranjera total. Pero tan pronto como hablo, comentan "Oh, iqué interesante! iQué catalán más bonito y perfecto que tienes!" (...) Debe de ser por mi piel oscura... Pero cuando abro la boca y hablo con este catalán tan acentuado, se les olvida mi negritud; todavía más cuando saben que uno de mis padres es súper blanco, y que estoy en la Universidad" Mujer de 22 años, madre española y padre ruandés.

"Nadie me identifica como española. En cambio, sí como brasileña, saharaui, marroquí, india, latinoamericana, pero colombiana no. Me ha pasado mucho de niña, de extraños en el autobús: "A ver, bonita, ¿y tú de dónde eres?" Yo de aquí [risas] Bueno, pues que tengo la carita [refiriéndose a su color oscuro de piel] y piensan que soy extranjera (...) Hay mucha diferencia entre mi hermana y yo; mi hermana es muy blanquita, a ella no se le nota, así que pasa desapercibida" Mujer, 27 años, padre español y madre colombiana.

Relacionado con lo anterior, las siguientes narrativas muestran con mayor claridad la relevancia del color de la piel para la inclusión social, el privilegio de la blanquitud dentro de la sociedad española (occidental), y las mayores opciones identitarias para aquellos individuos mixtos nacidos en España que no se identifican fácilmente como de origen extranjero:

"Para mí [ser mixto] no ha sido un problema. Más bien, ha sido una ventaja, porque sé otro idioma; también viajas mucho (...) No tengo acento italiano, así que puedo pasar desapercibido (...) Te miran y dicen: "iGuau, eres de otro lugar!" Quizás una persona de África podría ser más discriminada por ser negra, también los árabes" Hombre, 14 años, padre español y madre italiana.

"Ahora la gente mixta está mucho más aceptada socialmente, bueno al menos mucho más que la gente negra. [Ser mixto] me ha ayudado muchísimo (...) Porque aparte eso me da más conocimiento del inglés también y me hace no tener el acento africano de mi padre. Y me hace ser mucho más blanco de lo que sería (...) ser un negro-blanco [mixto] no es para nada lo mismo que ser un negro-negro. Aquí presente está mi pareja actual y creo que hasta ni siquiera la conocería si fuera negro-negro (...) La gente racializada está muy 
condicionada. Muchas veces me gustaría más ser blanco (...) Casi todos mis amigos son blancos, la gran mayoría, y yo patino y me gusta mucho salir de noche, y mis amigos son mucho más descarados que yo. Por experiencias que he tenido y que han tenido ciertos amigos míos, sé que no puedo serlo. Mis amigos pueden patinar delante de la policía o pueden beber delante de la policía, y yo sé que no puedo hacerlo, y ni se me pasa por la cabeza intentarlo. Antes de ayer hice un trabajo que era un anuncio para Latinoamérica y me dijeron literalmente que no querían que saliera mucho porque, aunque en Latinoamérica haya mucha gente de color no les gusta en general (...) Les gusta más la gente blanca que la gente negra, entonces no quieren que salga mucho en televisión gente negra. Y a mí me pusieron una máscara, mientras a los demás principales no" Hombre, 22 años, madre inglesa y padre camerunés.

Nuestro análisis de las narrativas con el software ATLAS.ti descubrió una variedad de términos recurrentes relacionados con los marcadores visibles y la discriminación. Hay muchas menciones al color de la piel, con términos despectivos específicos (por ejemplo: negro, blanco, mestizo, mulato, chocolate, Conguito, Cola Cao, moro, sudaca), y también términos relacionados el llamado micro-racismo (por ejemplo: mirada, rumor, sospecha, desconfianza, huelen mal, jodidos negros, jodidos inmigrantes), así como con sus consecuencias (por ejemplo: miedo, soledad, vergüenza, culpa, tristeza).

Uno de los marcadores más negativizados en este sentido es la descendencia de países del Magreb. El estigma proviene de tiempos de la "Reconquista", el conflicto entre cristianos y musulmanes que precedió a la era de Imperio español y colonización. Desde entonces, "los moros" han sido estigmatizados como extranjeros perpetuos, y la identidad española se ha creado en oposición al mundo musulmán (Mateo Dieste, 2018). Una islamofobia que se ha incrementado en los últimos años a raíz del yihadismo (Gottschalk y Greenberg, 2008). La islamofobia (o "morofobia") en España, hace que la interpretación de cualquier rasgo visible que remita a esta afiliación religiosa estigmatizada, como el color de piel oscuro, el idioma, acento o nombre árabe, o llevar puesto el hijab, se conviertan en significadores inmediatos de "musulmaneidad", colocando a la persona en una categoría social inferior que alienta la discriminación. Las siguientes narrativas ilustran bien este tipo particular de 
estigmatización que remite a la racialización del islam (Meer, 2014; Rodríguez-Reche y Rodríguez-García, 2020):

"He sufrido discriminación cuando estaba en la escuela, pero no por ser belgaruandesa, sino porque cuando no veían a mis padres la gente se pensaba que era marroquí. [Me llamaban] "mora de mierda" y cosas así (...) No sabían de donde podía venir yo, y por mi físico decían "esta es marroquí" (...) Al principio decía "no soy marroquí", y luego "¿Y qué si soy marroquí?". Es que aquí hay mucha discriminación con los marroquíes, muchísima" Mujer, 24 años, padre belga y madre ruandesa.

"A mi hermana melliza no le pasa tanto, porque ella no lleva velo, es más blanquita y lleva el pelo liso y tal... entonces lo que es físicamente normalmente no suele recibir comentarios. Pero claro, el hecho de llevar velo ya es como que la gente te ve más, destacas más. Yo voy por el metro y yo sé que la gente me está mirando, pero eso todos los días. O estar en algún sitio y que a ella le hablen en catalán, y que me miren a mí y me hablen en español" Mujer, 19 años, padre y madre marroquíes.

"Hace dos semanas un hombre me preguntó: "¿De dónde eres?". Supongo que porque desde que llevo esto [un collar con la mano de Fátima] mucha gente me pregunta. Y me dice: "Bueno, eres marroquí". Y le dije: "Bueno, si tú crees que sí no tengo ningún problema". Y dice: "Sí, eres morena, tienes rasgos y tienes el habla de allí". Y lo miré así ... Era una persona de unos 60 años y pensé ... Y me dice: "Y seguro que no hablas catalán". Y yo: "Señor he Nacido aquí en Barcelona, y sé más catalán que usted seguro", con educación..." Mujer, 22 años, padre español y madre marroquí.

Es importante señalar que también hemos encontrado experiencias de jóvenes descendientes de grupos estigmatizados que navegan en su mixticidad de forma más flexible y adaptativa y que expresan múltiples formas de resiliencia ante la discriminación, desafiando los estereotipos negativos de las categorías asignadas con auto-presentaciones estratégicas como motor de empoderamiento y agencia; por ejemplo reclamando sus raíces no occidentales / blancas como herramienta de orgullo étnico, tal y como ejemplificamos a continuación: 
"Yo siempre digo: no me gustan las etiquetas. Pero de lo que nunca renegaré es de que yo soy negro, ¿sabes? Y no tengo miedo de decirlo, ¿sabes? Y lo gritaré a los cuatro vientos, decir "soy negro y a buena honra". Estoy orgulloso de ser negro" Hombre, 25 años, padre y madre gambianos.

"¿Mi identidad? Una persona del mundo afrodescendiente (...) En tema de música pues cuando salimos de fiesta todo lo que buscamos es afrobeat [un estilo de música popularizado en África en los años 1970 que incorpora elementos de música yoruba, jazz, soul y funk]. iTodo lo que empiece por afro es bienvenido! [risas] Por ejemplo yo antes salir con mi pelo natural era imposible (...) no podía salir con el pelo sin alisarlo y cremas y potingues [blanqueadores de piel], hasta que un día dije "me corto el pelo, que empiece a crecer de nuevo" (...) [Desde entonces] Siempre llevo el afro natural, amo mi color de piel, salgo a la calle sin maquillarme cuando antes era imposible, me tenía que poner tres kilos de pote porque quería ser más blanca, ¿sabes? Un giro de 360 grados. O sea, si a mí me preguntas hace unos años atrás "¿qué quieres ser?" Digo: "blanca, no quiero ser morena, quiero tener el pelo liso, rubia, ojos azules". Pero es que ahora me lo preguntas y te digo: "iJoder! Ojalá fuera negra, negra, negra, tío, sería feliz, ojalá tuviera el pelo más prieto" Mujer, 18 años, madre colombiana y padre brasileño.

"Mirar redes sociales, páginas [de Twitter] como Afroféminas ... te enseñan a amar tu cabello. Porque mi madre es de República Dominicana y es un país muy racista, sobre todo con el cabello. Y claro, yo hacía lo que hacía mi madre: iba a la peluquería cada sábado, me alisaba el cabello... de hecho nunca quería salir a la calle con el pelo rizado, me daba mucha vergüenza. Hasta que este verano me corté el cabello, y dije "a partir de ahora cambio radical, debes aceptarte tal y como eres" Mujer, 19 años, padre español y madre dominicana.

En relación con la cuestión de la reivindicación étnico-racial y el empoderamiento-y de alguna forma como respuesta a la incapacidad de la academia y las instituciones políticas de abordar la cuestión de la raza en la realidad social- están emergiendo en España distintas formas de activismo, como el afrofeminismo, donde se hace una reapropiación de la identidad racializada y "visible" (es decir, el ser negro / afrodescendiente), como forma de empoderadoramiento y como estrategia antirracista y de-colonial (Grosfoguel, 2007). En España, ahora hay un número 
creciente de activistas sociales afrodescendientes, en su mayoría mujeres, como Lucía Mbombio o Desirée Bela-Lobedde, que lideran este movimiento sobre la negritud. Otras activistas, como Miriam Hatibi o Silvia Agüero, están haciendo lo mismo en torno a la islamofobia y el (anti) gitanismo, respectivamente. También hay una actividad creciente a nivel de organizaciones cívicas / comunitarias, así como a través de redes sociales como Twitter, con grupos como @Afrofeminas (también en web: https://afrofeminas.com), @blakbarcelona3, @Revista_Negrxs y @catarsiabcn, el último de los cuales es un colectivo antirracismo dirigido por activistas de ascendencia asiática. En este entorno, existen otros proyectos más específicos, como Afrofem Koop (https://afrofemkoop.wordpress.com) una iniciativa social cuyo objetivo es promover el desarrollo social, cultural, político y económico de las mujeres e identidades no binarias afrodescendientes. Todo esto no significa que no haya posicionamientos variados, incluso opuestos, dentro del activismo de los colectivos minorizados. En todo caso, no sentirse interpelado en esa forma de empoderamiento y lucha anti-racista que visibiliza el hecho social de la raza, no debería ir acompañado de una crítica condescendiente con quien sí lo hace.

\section{Conclusiones}

En este artículo, hemos argumentado que la idea de raza, vehiculada a través de la interpretación de marcadores visibles como el fenotipo, continúa siendo un factor clave en los procesos de estigmatización y discriminación en España.

Tras una contextualización histórica y sociodemográfica sobre el origen de la idea de raza y la prevalencia del racismo en España, hemos ofrecido algunos datos etnográficos sobre procesos de mixticidad en España, como prueba crucial para rastrear la pervivencia de la idea de raza. A partir de un análisis descriptivo-que sin ser exhaustivo sí creemos que ejemplifica bien la importancia de la cuestión de la visibilidad en los procesos de estigmatización y discriminación-hemos mostrado como aquellas personas que, independientemente de si son mixtos o no, pueden "pasar por autóctonos" (españoles nativos) porque comparten ciertas características visibles externas que les asemejan a la mayoría y que son socialmente prestigiosas (en particular el color/tono de piel blanco), son menos estigmatizados que los descendientes de parejas mixtas cuyos marcadores visibles no prestigiados 
socialmente (e.g., un color de piel oscuro), son tratados como extranjeros. Otros estudios con población mixta en diferentes países han encontrado resultados similares (e.g., Waters, 1996 en Estados Unidos, Brinbaum et al., 2018 en Francia, o Gilliéron, 2017 en Suiza).

Esta información es relevante, pues las construcciones raciales que privilegian la "blanquitud" y que sirven para distinguir entre "nosotros" y "los otros", afectan a las personas de las "minorías visibles" en su vida cotidiana. Cuando una maestra de tercer grado le dice a una niña de 8 años de padre español y madre dominicana que, por ser negra, interpretará al lobo en Caperucita Roja, o cuando un propietario se niega a alquilar un apartamento a alguien en base puramente en la apariencia física de esa persona, estamos, sin lugar a dudas, hablando del hecho social de la raza, de racialización y de racismo, no de algo abstracto o inexistente, es decir, sin impacto en la vida de la gente.

Por supuesto, la diferencia o la diversidad en general, no solo se definen en base al hecho racial. Existen muchas otras formas de diversidad y posicionalidad, basadas en el origen, el género, la clase social, la orientación sexual, o la edad. Pero eso no evita el hecho de que la idea de raza siga siendo una parte crucial de la ecuación. De hecho, la raza intersecciona inevitablemente con las demás dimensiones de la diversidad (Anthias, 2020). Por otro lado, el hecho de que las diferencias o posicionalidades sean múltiples, contextuales y cambiantes, y que puedan implicar resiliencia y empoderamiento (Deaux, 2018; Giliberti, 2013), como también hemos mostrado en algunos ejemplos de narrativas, no implica que la problematización de esas diferencias desaparezca.

El hecho de que prácticamente no hayamos encontrado diferencias entre las experiencias de estigmatización y discriminación vividas por individuos mixtos y los descendientes de parejas endógamas que comparten los mismos marcadores estigmatizadores (para un análisis más profundo véase Rodríguez-García et al., 2021b), no solo pone de manifiesto la persistencia de la idea de raza, sino que también desafía la noción idealizada de un futuro de mestizaje sin racismo, tal como proponían las teorías clásicas de la asimilación (Gordon, 1964). Paradójicamente, los procesos de mixticidad en España coexisten con la persistente estigmatización y discriminación de ciertos grupos, marcados en gran medida por sus diferencias visibles percibidas y construidas históricamente; siendo dos de las pervivencias más 
importantes la estigmatización de la herencia negro-africana y del islam, como señalan también otros estudios (Chito Childs, 2014; DaCosta, 2020; Khanna, 2010; Lee y Bean, 2012; Rodríguez-García 2015; Rodríguez-Reche y Rodríguez-García, 2020; Rodríguez-García et al., 2021b; Song, 2014a; Spencer, 2011).

El predominio del sentimiento anti-musulmán en España (Europa) complica todavía más el análisis y la teorización en torno a la idea de raza y el racismo, pues descubrimos que otras dimensiones de la diversidad, como la religión, pueden ser racializadas y convertirse en marcadores tan divisorios y marginalizadores como la idea clásica de raza (Foner, 2015; Grosfoguel, 2004; Rodríguez-Reche y RodríguezGarcía, 2020).

Es todavía más sorprendente que nuestros hallazgos etnográficos se refieran a Cataluña, una región de España que ha sido tradicionalmente construida gracias a la inmigración, y con un modelo de integración propio que se define en términos de integración y mezcla (Domingo, 2014).

En definitiva, mientras España (Europa) se piensa a sí misma como una sociedad post-racial que ha superado su pasado colonialista y en la que todos los ciudadanos son tratados por igual, las disparidades según los orígenes etnoraciales, que tienen sus raíces en desventajas históricas, continúan existiendo en todos los ámbitos de la estructura social. El racismo y la racialización están tan profundamente arraigados en el orden social que estos procesos a menudo se pasan por alto, como vimos con el ejemplo aparentemente trivial de los Conguitos.

En este contexto, coincidimos con autores como Beaman (2019), Bonilla-Silva (1999, 2013), Mazzocco (2015), Simon (2019), Song (2018) o St Louis (2016), en que las benevolentes teorías liberales contemporáneas de la ciudadanía global, con su distintivo enfoque post-racial o "daltónico" (colorblind ${ }^{18}$ o ciego al color) y el uso de un lenguaje eufemístico frente a la raza, invisibilizan las diferencias y socavan nuestra capacidad para exponerlas como base para el racismo, contribuyendo a normalizarlo y perpetuarlo. En última instancia, una perspectiva post-racial en una sociedad donde

\footnotetext{
18 Según Bonilla-Silva (2013), "racismo daltónico" (colorblind racism) se refiere a la ideología racial blanca dominante de la era moderna, en la que los blancos se niegan a reconocer la realidad del racismo y rechazan cualquier consideración de cómo su propia identidad racial blanca les otorga privilegios frente a las personas de color.
} 
persiste la estratificación racial, como es el caso de España y de la mayoría de los países europeos, ayuda a mantener las dimensiones simbólicas, institucionales e interpersonales del racismo. Una visión post-racial, aunque en teoría puede parecer justa y sensata, es injusta además de poco práctica, ya que homogeneiza aspectos de la diversidad y limita la discusión sobre las diferencias que generan la desigualdad, favoreciendo posiciones privilegiadas (Young, 1990).

En conclusión, consideramos que, dado que el racismo no existe sin la idea de raza (Golash-Boza, 2016), y que se trata de un fenómeno estructural (Hall, 1980), solo articulando y visibilizando las conexiones entre las ideologías de la raza y las estructuras racistas, será posible combatir el racismo de forma efectiva. En un contexto de creciente racismo y de aumento de las ideologías de extrema derecha en todo el mundo, nos parece esencial fomentar un debate maduro, valiente $y$ constructivo sobre el hecho social de la raza, la racialización y el racismo, donde académicos, junto con responsables políticos y profesionales del tercer sector, combinen esfuerzos para alcanzar mayores cotas de igualdad y cohesión social.

\section{Bibliografía}

Ajuntament de Barcelona. (2020). Informe Observatori Discriminacions de Barcelona 2019. Barcelona: Ajuntament de Barcelona.

Alba, R., Nancy, F. (2015). Strangers No More. Immigration and the Challenge of Integration in North America and Western Europe. Princeton: Princeton University Press.

Anthias, F. (2020). Translocational Belongings: Intersectional Dilemmas and Social Inequalities. Routledge: London \& New York.

Arango, J. (2013). Exceptional in Europe? Spain's Experience with Immigration and Integration. Washington, DC: Migration Policy Institute.

Balibar, E., Immanuel, W. (1991). Race, Nation, and Class: Ambiguous Identities. Londres: Verso.

Ballestín González, B. (2011). Los niños de la inmigración en la escuela primaria: identidades y dinámicas de des/vinculación escolar, entre el colourblindness y los esencialismos culturalistas. En Franzé, A. et al. (Eds.) Etnografías de 
la infancia y de la adolescencia. Barcelona: La Catarata, 133-159.

Ballestín González, B. (2012). "iDile al negrito y al cola cao que paren de molestarnos!. Sociabilidad entre iguales y dinámicas de segregación en la escuela primaria." En García Castaño, J. y Olmos, A. (Eds.) Segregaciones y construcción de la diferencia en la escuela. Madrid: Trotta.

Barker, M. (1981). The New Racism. London: Junction Books.

Barot, R., John, B. (2001). Racialization: the genealogy and critique of a concept. Ethnic and Racial Studies, 24 (4), 601-618.

Beaman, J. (2019). Are French people white? Towards an understanding of whiteness in Republican France. Identities, 26 (5), 546-562.

Bonilla-Silva, E. (1999). The Essential Social Fact of Race. American Sociological Review, 64 (6), 899-906.

Bonilla-Silva, E. (2013). Racism without Racists: Color-blind Racism and the Persistence of Racial Inequality in America. Lanham: Rowman \& Littlefield.

Brinbaum, Y., Mirna, S., Patrick, S. (2018). "Discrimination in France: Between Perception and Experience". En Beauchemin, C., Hamel, C. y Simon, P. (Eds.) Trajectories and Origins: Survey on the Diversity of the French Population (195-222). Paris: Springer, Col. INED Population Studies.

Campos, A. (2012). Racialización, racialismo y racismo: un discernimiento necesario. Universidad de la Habana 273, 184-199.

Campos, R. (2016). Authoritarianism and punitive eugenics: Racial hygiene and national Catholicism during Francoism, 1936-1945. História, Ciências, SaúdeManguinhos, 23 (1), 131-148.

CEDRE (Consejo para la Eliminación de la Discriminación Racial o Étnica). (2020). Percepción de la discriminación por origen racial o étnico por parte de sus potenciales víctimas en 2020. Madrid: Ministerio de Igualdad, Subdirección General para la Igualdad de Trato y Diversidad Étnico Racial.

Chito Childs, E. (2014). A Global Look at Mixing: Problems, Pitfalls and Possibilities. Journal of Intercultural Studies, 35 (6), 677-688.

Chun, E., Adrienne, L. (2015). Language and racialization. En Bonvillains, N. 
(Ed.) The Routledge Handbook of Linguistic Anthropology (220-232). New York: Routledge.

Cornejo, R. (Coord.) (2007). Memoria colonial e inmigración: la negritud en la España posfranquista. Barcelona: Bellaterra.

DaCosta, K. (2020). Multiracial Categorization, Identity, and Policy in (Mixed) Racial Formations. Annual Review of Sociology, 46. DOI: 10.1146/annurev-soc121919-054649

Deaux, K. (2018). Ethnic/Racial Identity: Fuzzy Categories and Shifting Positions. The Annals of the American Academy of Political and Social Science, 677 (1), 39-47.

Domingo, A. (2014). Catalunya al mirall de la immigració: Demografia $i$ identitat nacional. Barcelona: Avenç.

Essed, P. (1991). Understanding everyday racism. An interdisciplinary theory. London: Sage.

European Union Agency for Fundamental Rights. (2018). Being Black in the EU/Second European Union Minorities and Discrimination Survey (EU-MIDIS II). https://fra.europa.eu/en/publication/2018/eumidis-ii-being-black

Federación de Asociaciones de SOS Racismo. (2015). Puertas que se cierran. Testing sobre discriminación a la población inmigrante en el acceso a la vivienda de alquiler. Donostia: SOS Racismo. https://sosracismo.eu/wpcontent/uploads/2016/07/Puertas-que-se-cierran-Testing.pdf

Federación de Asociaciones de SOS Racismo. (2019). Informe identificacions policials $i$ perfilació ètnica a Catalunya. Barcelona: SOS Racisme. https://www.pareudepararme.org/informe-ca/

Flores, R. (2015). The Resurgence of Race in Spain: Perceptions of Discrimination among Immigrants. Social Forces, 94 (1), 237-269.

Foner, N. (2015). Is Islam in Western Europe Like Race in the United States? Sociological Forum, 30 (4), 885-899.

Gans, H. (2017). Racialization and racialization research. Ethnic and Racial Studies, 40 (3), 341-352. 
García Canclini, N. (1995). Hybrid Cultures: Strategies for Entering and Leaving Modernity. Minneapolis: University of Minnessota Press.

Giliberti, L. (2013). La condición inmigrante y la negritud en la experiencia escolar de la juventud dominicana: estigmas y formas de agencia. Una etnografía transnacional entre la periferia de Barcelona y Santo Domingo. Tesis de Doctorado: Universidad de Lleida.

Gilliéron, G. (2017). Couples mixtes et transmissions familiales: la construction identitaire de jeunes adultes binationaux. Le carnet de recherche du Centre Jacques Berque. https://cjb.hypotheses.org/517

Golash-Boza, T. (2016). A Critical and Comprehensive Sociological Theory of Race and Racism. Sociology of Race and Ethnicity, 2 (2), 1-13.

Goldberg, D. (2002). The Racial State. Malden: Blackwell.

Goldberg, D. (2006). Racial Europeanization. Ethnic and Racial Studies, 29 (2), 331-364.

Gordon, M. (1964). Assimilation in American Life. New York: Oxford University Press.

Gottschalk, P., Greenberg, G. (2008). Islamophobia: Making Muslims the enemy. Plymouth: Rowman \& Littlefield.

Grosfoguel, R. (2004). Race and Ethnicity or Racialized Ethnicities?: Identitites within Global Coloniality. Ethnicities, 4 (3), 315-336.

Grosfoguel, R. (2007). The Epistemic Decolonial Turn: Beyond Political Economy Paradigms. Cultural Studies, 21 (2-3), 211-223.

Gross, D., Matthew, H. (2017). Racialization. En Turner, B.S., Kyung-Sup, C., Epstein, C.F., Kivisto, P., Ryan, J.M., y Outhwaite, W. (Eds.) The Encyclopedia of Social Theory. New Jersey: Wiley-Blackwell.

Hall, S. (1980). Race, Articulation, and Societies Structured in Dominance. En Sociological Theories: Race and Colonialism (305-345). Paris: UNESCO.

Hochman, A. (2019). Racialization: a defense of the concept. Ethnic and Racial Studies, 42 (8), 1245-1262. 
Hughey, M. (2017). Race and Racism: Perspectives from Bahá'í Theology and Critical Sociology. Journal of Bahá'í Studies, 27 (3), 7-56.

Hunter, M. (2007). The persistent problem of colorism: Skin tone, status, and inequality. Sociology Compass, 1 (1), 237-254.

Jenkins, R. (1997). Rethinking ethnicity. Arguments and explorations. London: SAGE.

Khanna, N. (2010). 'If You're Half Black, You're Just Black:' Reflected Appraisals and the Persistence of the One-Drop Rule. Sociological Quarterly, 51 (1), 96-121.

Lee, J., Frank, B. (2012). A Postracial Society or a Diversity Paradox? Race, Immigration, and Multiraciality in the Twenty-First Century. Du Bois Review: Social Science Research on Race, 9 (2), 419-437.

Lentin, A. (2008). Europe and the Silence about Race. European Journal of Social Theory, 11 (4), 487-503.

Lentin, A. (2020). Why Race Still Matters. Cambridge: Polity Press.

Lewis, A. (2004). "What Group?" Studying Whites and Whiteness in the Era of Color-Blindness. Sociological Theory, 22 (4), 623-646.

Lewontin, R., Steven, R., Leon, K. (1985). Not in Our Genes: Biology, Ideology, and Human Nature. New York: Pantheon.

Martin, H., Derrick, H., Cedric, H., Verna, K., Melvin, T. (Wds.) (2017). Color Struck. How Race and Complexion Matter in the "Color-Blind" Era. Rotterdam, Boston and Taipei: Sense Publishers.

Mateo Dieste, J.L. (2018). Moros vienen. Historia y política de un estereotipo. Melilla: Instituto de las culturas.

Mazzocco, P. (2015). Talking productively about race in the colorblind era. Kirwan Institute Research Report. Columbus, $\mathrm{OH}$ : The Ohio State University.

Méchoulan, H. (1981). El honor de Dios. Indios, judíos y moriscos en el Siglo de Oro. Madrid: Argos Vergara.

Meer, N.(Ed.) (2014). Racialization and religion: Race, culture and difference in the study of antisemitism and Islamophobia. Ethnic and Racial Studies Series. 
Abingdon: Routledge.

Molina, J.L., Rodríguez-García, D. (2018). Ethnicity, Multiculturalism, and Transnationalism. En Callan, H. (Ed.) The International Encyclopedia of Anthropology. New Jersey: Wiley-Blackwell.

Murji, K., Solomos, J. (Eds.) (2005). Racialization: Studies in Theory and Practice. New York: Oxford University Press.

Price, P. (2012). Race and Ethnicity II: Skin and other intimacies. Progress in Human Geography, 37 (4), 578-586.

Rodríguez-García, D. (2021). Forbidden Love: Controlling Partnerships Across Ethnoracial Boundaries. En Mayer, C. y Vanderheiden, E. (Eds.) International Handbook of Love: Transcultural and Transdisciplinary Perspectives (923-942). Switzerland: Springer.

Rodríguez-García, D. (2015). Introduction: Intermarriage and Integration Revisited: International Experiences and Cross-disciplinary Approaches. The Annals of the American Academy of Political and Social Sciences, 662 (1), 8-36.

Rodríguez-García, D., de Miguel Luken, V., Solana, M. (2021a). Las uniones mixtas y sus descendientes en España: evolución y consideraciones sobre la mixticidad". En Arango, J. et al. (Dirs) Anuario CIDOB de la Inmigración 2020 (168195). Barcelona: CIDOB.

Rodríguez-García, D., Miguel Luken, V. de (2015). Matrimonis mixtes i fills de la barreja a Catalunya: dels 'xarnegos' als 'cafè amb llet'?. En Domingo, A. (Coord.) Migracions dels segles XX i XXI a Catalunya. Una mirada Candeliana (193-218). Barcelona: Generalitat de Catalunya, Departament de Benestar Social i Família, Direcció General per a la Immigració. Col·lecció Ciutadania i Immigració 11.

Rodríguez-García, D., Solana, M., Ortiz, A, Freedman, J. (2018). "Linguistic Cultural Capital among Descendants of Mixed Couples in Catalonia, Spain: Realities and Inequalities." Journal of Intercultural Studies 39 (4), 429-450.

Rodríguez-García, D., Solana, M., Ortiz, A., Ballestín, B. (2021b). Blurring of Colour Lines? Ethnoracially Mixed Youth in Spain Navigating Identity. Journal of Ethnic and Migration Studies, 47 (4), 838-860. 
Rodríguez-Reche, C., Rodríguez-García, D. (2020). El estigma de la musulmaneidad: visibilidad percibida y racismo en hijas de parejas mixtas con padre/madre de origen magrebí en Barcelona y Granada. Perifèria, revista de recerca i formació en antropologia, 25 (1), 4-27.

Simon, P. (2019). L'antiracisme et la race: colorblindness et privilège blanc. Les Possibles 21, Été 2019.

Song, M. (2014a). Does a Recognition of Mixed Race Move us Toward PostRace? En Murji, J., Solomos, J. (Eds.) Theories of Race and Ethnicity: Contemporary Debates and Perspectives (15-36). Cambridge: Cambridge University Press.

Song, M. (2014b). Challenging a culture of racial equivalence. The British Journal of Sociology, 65 (1), 107-129.

Song, M. (2018). Why we still need to talk about race. Ethnic and Racial Studies, $41(6), 1131-1145$.

Spencer, R. (2011). Reproducing Race: The Paradox of Generation Mix. Boulder, CO: Lynne Rienner.

St Louis, B. (2016). Can Race Be Eradicated? The Post Racial Problematic. En Murji, K., Solomos, J. (Eds.) Theories of Race and Ethnicity: Contemporary Debates and Perspectives (114-138). Cambridge: Cambridge University Press.

Sue, D. (2010). Microaggressions in Everyday Life: Race, Gender, and Sexual Orientation. Hoboken, NJ: Wiley.

Telles, E. (2014). Pigmentocracies. Ethnicity, race, and color in Latin America. Chapel Hill, NC: University of North Carolina Press.

Waters, M. (1996). Optional Ethnicities: For Whites Only? En Pedraza, S., Rumbaut, R.G. (Eds.) Origins and Destinies: Immigration, Race and Ethnicity in America (444-454). Belmont, CA: Wadsworth Publishing Company. 